\title{
Quantifying and modelling fabric anisotropy of granular soils
}

\author{
Z. X. YANG*, X. S. LI† and J. YANG*
}

This paper describes an integrated study of the effects of fabric anisotropy on granular soil response, in which the microscopic measurements are properly linked with the macroscopic modelling. Using an image-analysis-based technique and an appropriate mathematical approach, the inherent fabrics of sand specimens prepared in the laboratory using different sample preparation methods were measured, quantified and compared at a microscale level. It was found that the specimen prepared by the dry deposition method had a more anisotropic microstructure than the specimen prepared using the moist tamping method, which is considered directly associated with the experimental observation that different sample preparation methods produce samples with distinctive responses under otherwise identical conditions. An existing platform model was then extended so that the combined effects of initial fabric and shear mode dependence were accounted for in a simple yet rational manner. To calibrate and verify the model, a series of laboratory tests was conducted for Toyoura sand under various combinations of loading and sample preparation conditions. It is shown that the model is capable of simulating in a unified manner the experimental results reflecting the combined effects of sample preparation methods, loading paths, soil densities and confining pressures.

KEYWORDS: anisotropy; constitutive relations; fabric; microstructure; plasticity; sands
La présente communication décrit une étude intégrée des effets anisotropes de la structure sur la réponse du sol granulaire, dans laquelle on met correctement en rapport les mesures microscopiques et la modélisation macroscopique. En utilisant une technique basée sur l'analyse d'images, et une méthode mathématique appropriée, on a mesuré, quantifié et comparé, au niveau de la microéchelle, les structures inhérentes de spécimens de sable préparés en laboratoire, en appliquant différentes méthodes de préparation des échantillons. On a relevé que le spécimen préparé par retombée sèche présentait une structure plus anisotrope que le spécimen préparé avec la méthode de pilonnage humide, et l'on considère que ceci est en rapport direct avec l'observation expérimentale d'après laquelle différentes méthodes de préparation des échantillons produisent des échantillons présentant des réponses caractéristiques, les autres conditions étant identiques. On a ensuite développé un modèle à plate-forme existant, afin de définir, de façon à la fois simple et rationnelle, les effets conjugués de la structure initiale et de la dépendance du mode de cisaillement. Pour calibrer et vérifier le modèle, on a effectué une série d'essais en laboratoire pour le sable Toyoura, en appliquant différentes combinaisons de charges et de préparation des échantillons. On démontre que le modèle est en mesure de simuler, de façon harmonisée, les résultats expérimentaux reflétant les effets conjugués des méthodes de préparation des échantillons, des chemins de charge, de la densité du sol, et des pressions de confinement.

\section{INTRODUCTION}

It has been consistently observed that two specimens of a granular soil, prepared by different methods in the laboratory, may exhibit quite different responses to applied loading under otherwise identical conditions (Miura \& Toki, 1982; Tatsuoka et al., 1986; Vaid et al., 1999). This observation is highlighted in Fig. 1(a), where undrained responses of two Toyoura sand samples, prepared respectively by the dry deposition and moist tamping methods and subjected to monotonic triaxial compression, are compared in the plane of deviatoric and mean effective stresses. Clearly, the specimen prepared by the moist tamping method displays a stronger resistance to the build-up of pore water pressure and a more dilative response than the specimen prepared by the dry deposition method. Since both specimens are of the same density and subjected to the same initial confining pressure and loading path, the difference observed in Fig. 1(a) is considered directly associated with the distinctive fabrics of the two specimens.

Manuscript received 1 August 2006; revised manuscript accepted 31 October 2007

Discussion on this paper closes on 1 November 2008, for further details see $p$. ii.

* Department of Civil Engineering, The University of Hong Kong; currently Department of Civil Engineering, Zhejiang University, China.

$\dagger$ Department of Civil Engineering, Hong Kong University of Science and Technology.
On the other hand, a number of experimental investigations have indicated that two specimens of a granular soil, even when prepared using the same method and sheared at the same initial state (accounting for both density and pressure), may exhibit different responses if the loading paths applied to them are different (Vaid \& Chern, 1985; Riemer \& Seed, 1997; Yoshimine et al., 1998). Shown in Fig. 1(b) are undrained responses of three samples of Toyoura sand prepared using the moist tamping method; one of them is subjected to monotonic triaxial compression, one to triaxial extension, and one to torsional shear. Note that the specimen in extension is much more contractive than that in compression, with the torsional shear in between. This difference is another indication of anisotropy, which is believed related to the orientation of the major principal stress direction with reference to the deposition plane of the samples.

While there is abundant evidence of the impact of fabric anisotropy on granular soil behaviour as shown above, it remains a challenging task to take the anisotropic effects into account in geotechnical analysis and design. The primary difficulties lie in (a) how to effectively quantify the fabric anisotropy and (b) how to rationally introduce the anisotropic effects into the well-established continuum mechanics framework. To handle the first problem, an appropriate experimental approach to collecting the information on the microstructure of a granular soil assembly and a mathematical approach to describing the fabric anisotropy objectively are required. The second problem requires a proper link to be established between the microscale measurements and the 


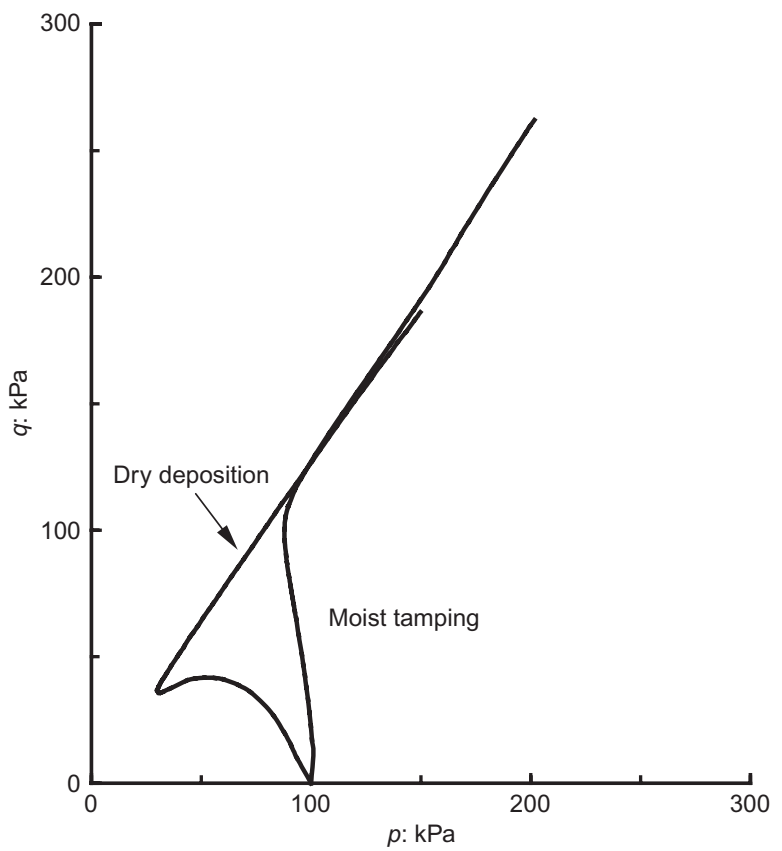

(a)

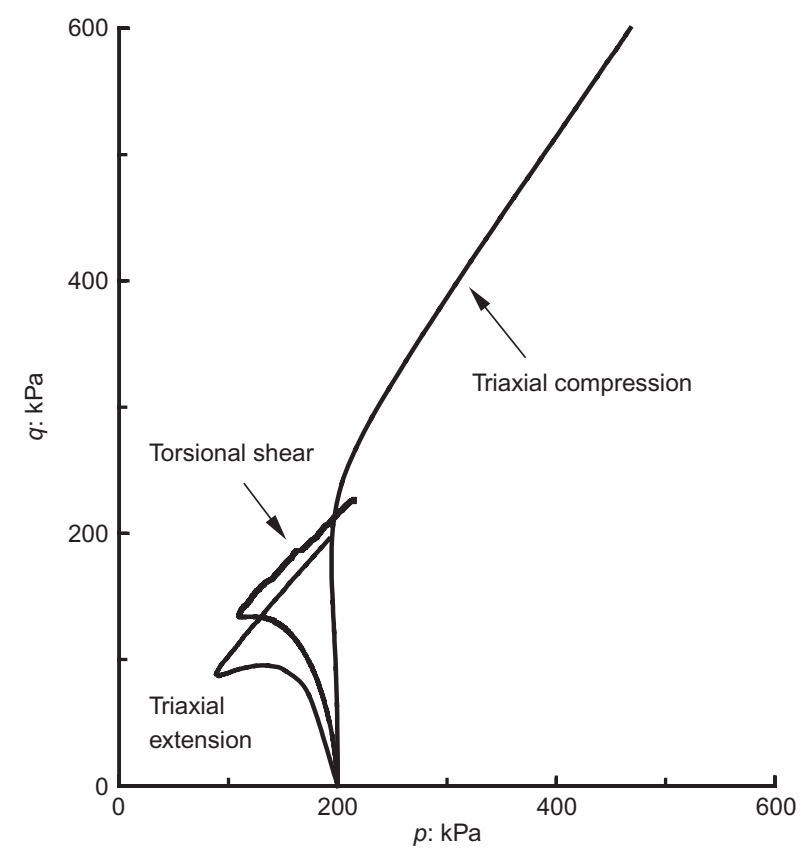

(b)

Fig. 1. Effects of sample preparation methods and loading paths on undrained response of Toyoura sand: (a) in triaxial compression $\left(D_{\mathrm{r}}=20 \%\right)$; (b) prepared by moist tamping $\left(D_{\mathrm{r}}=30 \%\right)$

macroscopic stress-strain-strength behaviour and a strategic model calibration and verification. For reasons of simplicity, the influence of soil fabric anisotropy has been largely ignored or treated crudely in geotechnical analyses.

A strong motivation for a serious treatment of the fabric anisotropy of granular soils has arisen in recent years from great uncertainties in the analysis of flow liquefaction deformation and the determination of the undrained critical state or steady-state strength (Finn, 2000; Yang, 2002). A backanalysis of the failed Lower San Fernando Dam (Finn, 2000) indicated that the average steady-state strength of sand was only $35 \%$ of the laboratory triaxial compression value, which had already been reduced by a factor of 6.5 to correct for disturbance (Seed et al., 1989). This observation does not fit he established theory of critical-state soil mechanics, in which the undrained critical-state strength of a soil is a function only of its void ratio or density. On the contrary, it has been consistently observed that the undrained response of a granular soil and its critical-state strength may depend on the stress path and initial fabric as well.

This paper presents an investigation into fabric anisotropy effects on granular soil behaviour, in which the two primary problems mentioned above were addressed in an integrated manner. First, an image-analysis-based technique combined with a mathematical approach was developed to measure and quantify the initial fabric of a granular soil assembly at the microscale level. The different fabrics formed by two sample preparation methods widely used in the laboratory were identified and compared. Second, an existing platform model (Li \& Dafalias, 2002) was extended to account for the combined effects of inherent fabric and loading direction on granular soil response in a tractable way. Third, a series of laboratory tests was conducted on Toyoura sand under various loading and sample preparation conditions. Detailed comparisons of the model simulations and test results are made to assess the model performance in capturing the fabric anisotropic effects.

\section{MEASUREMENT OF FABRIC ANISOTROPY}

Measuring the fabric of a granular soil assembly is of fundamental importance, yet it is a challenge in the study of anisotropy effects. Available experimental data on soil fabric are scarce. In recent years image analysis has emerged as a promising technique in geotechnical research, because it allows the soil structure to be characterised at the microscale level (Kuo \& Frost, 1996; Jang et al., 1999). In doing this, the fabric of a soil specimen should be preserved in a manner with minimum disturbance, and the representative coupon surfaces are then sectioned for image analysis by a scanning electron microscope (SEM). Generally, there are two methods for preservation of the fabric of a granular soil specimen: one is to impregnate the specimen with resin and cure it, and the other is to saturate the specimen with water and freeze it. Of these two methods, the former is considered more viable, because a frozen specimen may not be strong enough to sustain sectioning, grinding and polishing in the process of acquiring high-quality coupon surfaces for image analysis.

In this study Toyoura sand, a Japanese standard sand consisting of subrounded to subangular particles, was used. The basic properties of this sand are: mean diameter = $0.23 \mathrm{~mm}$; uniformity coefficient $=1 \cdot 32$; specific gravity $=$ 2.65 ; maximum void ratio $=0.977$; and minimum void ratio $=0.597$. Both the dry deposition and moist tamping methods (Ishihara, 1993) were employed to produce specimens for laboratory testing. In the dry deposition (DD) method, ovendried sand is filled into the mould in several layers using a funnel. In each layer the sand is poured by keeping the funnel's nozzle slightly above the sand surface so that the sand is deposited in the loosest state. A denser specimen of target density can be prepared by tapping the mould using a rubber mallet. In the moist tamping (MT) method, moist sand (typically with $5 \%$ water content) is placed in five or ten layers in the mould. In each layer a tamper is used to compact the sand. The tamping energy applied to the upper layers is generally higher than that to the lower layers, so that a relatively uniform density can be achieved. Generally, the dry deposition method is considered suitable for modelling the natural deposition process, whereas the moist tamping method can model the soil fabric of rolled construction fills better, and has the advantage of preventing segregation of wellgraded materials (Kuerbis \& Vaid, 1988; Ishihara, 1993). 
Specimen impregnation

A traditional triaxial cell was modified for epoxy impregnation (Fig. 2), which was performed by forcing epoxy resin into the soil specimen under a low differential pressure of about $20-30 \mathrm{kPa}$. The low pressure and slow epoxy flow were maintained to minimise the disturbance to the soil fabric and to prevent air bubbles from being trapped in the soil sample. Since the epoxy will not function well in moist conditions, the initial moisture in soil specimens prepared by the MT method should be completely removed by drying before epoxy impregnation. To achieve this, a system was designed and fabricated to facilitate drying of the specimens without causing disturbance (Fig. 3). The drying process used was essentially the same as that used by Jang et al. (1999). Compared with the vacuum pressure of $15 \mathrm{kPa}$ recommended by Jang et al. (1999) for the drying process, an even smaller vacuum of about $5 \mathrm{kPa}$ was used to minimise potential disturbance.

The desiccant $\mathrm{CaSO}_{4}$ was employed in this study because it functions better in a low-moisture environment than the commonly used silica gel. It turns from blue into pink when hydration takes place, and can thus serve as a moisture indicator. For the MT specimen the drying process normally required about $24 \mathrm{~h}$ to remove all the water in the soil under a vacuum of $5 \mathrm{kPa}$. Following epoxy impregnation, the epoxy resin needs to be cured until the specimen is hardened with sufficient bonding strength.

\section{Coupon surface preparation}

The hardened specimen was cut into small patches using a band saw, and the small patches were then sectioned using a diamond saw into thin layers with workable dimensions $(20 \mathrm{~mm} \times 20 \mathrm{~mm} \times 10 \mathrm{~mm})$ for grinding and polishing. The grinding and polishing are crucial in the preparation of coupon surfaces for soil structure identification, because quantitative measurement demands a high feature contrast and a high accuracy of the surface images. For statistical considerations, the images captured should be representative and lie in different locations. In this study, only the horizontal and vertical sections were chosen for consideration (Fig.

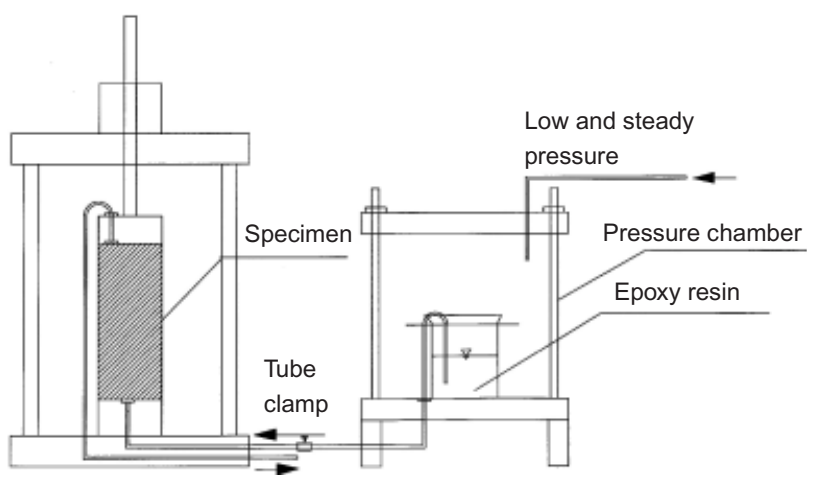

Fig. 2. Epoxy impregnation system

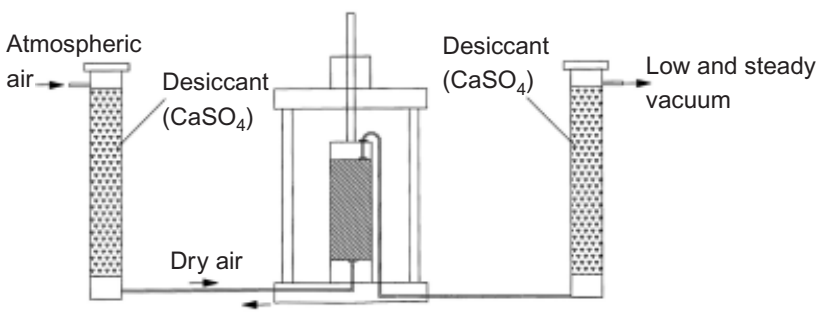

Fig. 3. Drying system for moist tamped specimen
4) because the samples prepared by the DD and MT methods were essentially transversely isotropic, with the vertical axis as the axis of symmetry.

\section{Image capture and analysis}

After sectioning, grinding and polishing, the coupon surfaces then qualified as SEM specimens. But before images were taken, the coupons were placed in a desiccant case for complete drying to avoid contamination of the SEM. The image capture was ready after a $10 \mathrm{kV}$ voltage was applied. Adjusting the contrast and focusing at large magnification, say 200 , the desired image could be obtained. For representative purposes the magnification was fixed at 30 , and the corresponding image had $1024 \times 819$ pixels.

Figure 5 shows a typical SEM image at a magnification of 200. This figure clearly shows the sand particles surrounded by the epoxy matrix. Some air bubbles in dark and circular shapes and lost sand particles due to the damage from coupon surface preparation are observed. Examples of a typical image captured by SEM and black-and-white mask (binary image) used for image analysis are given in Fig. 6. The size of patches generally has to be restricted for use in SEM. To consider possible local variations in the fabric, a set of neighbouring images rather than only a single image as shown in Fig. 6 were used in the fabric analysis. The number of particles contained by one typical image (Fig. 6) was around 300 , whereas the number of particles used in the fabric analysis (i.e. vector magnitude) was up to 1700 (Table 1).

\section{VECTOR MAGNITUDE AND FABRIC TENSOR}

A random packing of non-spherical particles possesses statistical characteristics in the spatial arrangement of the particles and associated voids. Curray (1956) proposed a vector magnitude $\Delta$ to characterise the intensity of anisotropy of the preferred particle orientation. The index $\Delta$ takes the form

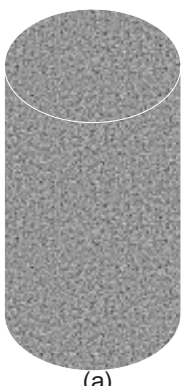

(a)

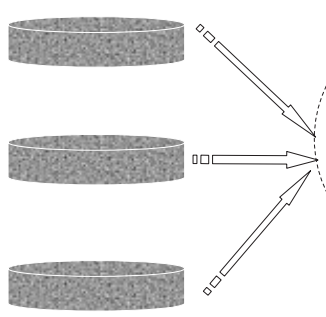

(b)

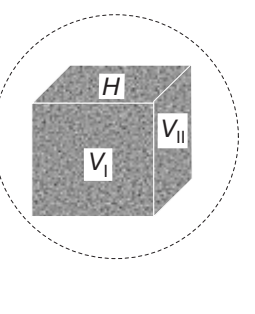

Fig. 4. Coupon sectioning for image analysis: (a) epoxyimpregnated specimen; (b) sectioning along different locations; (c) enlarged view of a patch used for analysis

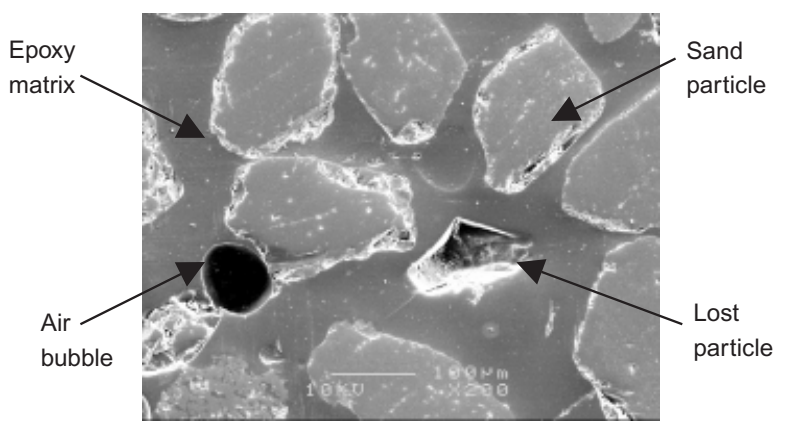

Fig. 5. A typical SEM image 


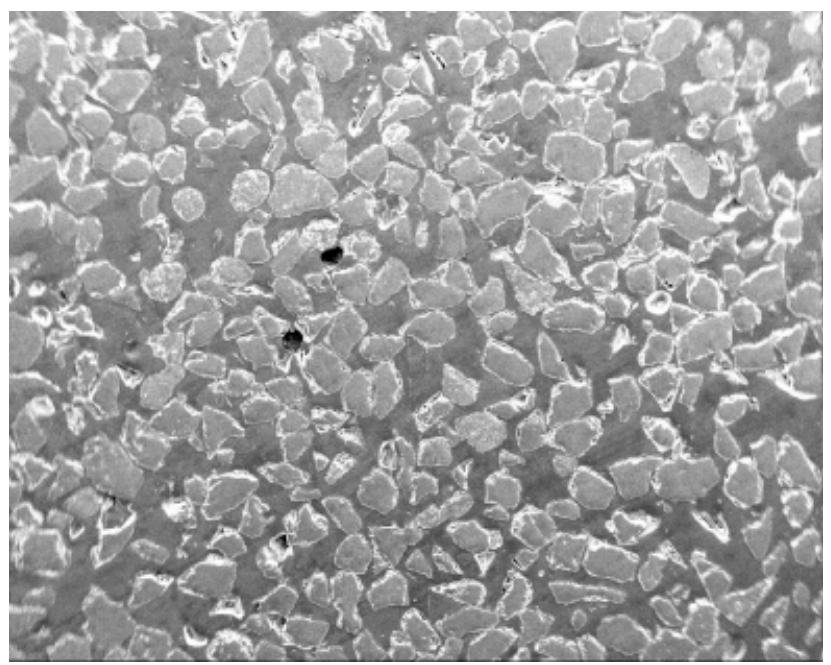

(a)

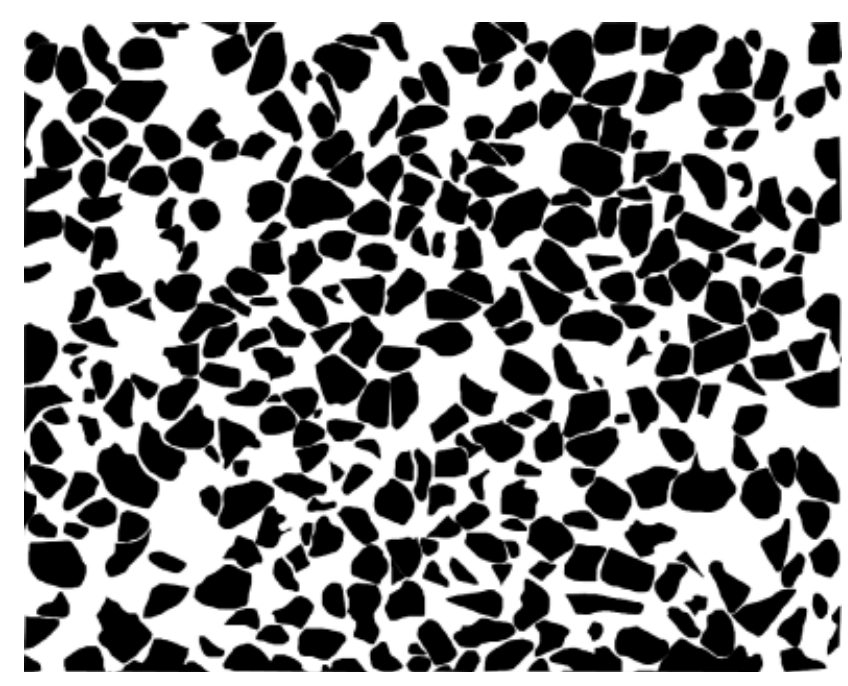

(b)

Fig. 6. Typical SEM image of a thin section: (a) SEM microphotograph; (b) $\mathrm{B} / \mathrm{W}$ mask for image processing

$$
\Delta=\frac{1}{2 N} \sqrt{\left(\sum_{k=1}^{2 N} \cos 2 \phi_{k}\right)^{2}+\left(\sum_{k=1}^{2 N} \sin 2 \phi_{k}\right)^{2}}
$$

where $\phi_{k}$ is the inclination angle of the $k$ th unit vector $\mathbf{n}$, measured with reference to the $H_{1}$ axis in a representative $V-H_{1}$ section (Fig. 7). The value of $\Delta$ depends on the particle shape and the process of soil deposition. It varies from zero, when the material is isotropic, to unity, when the

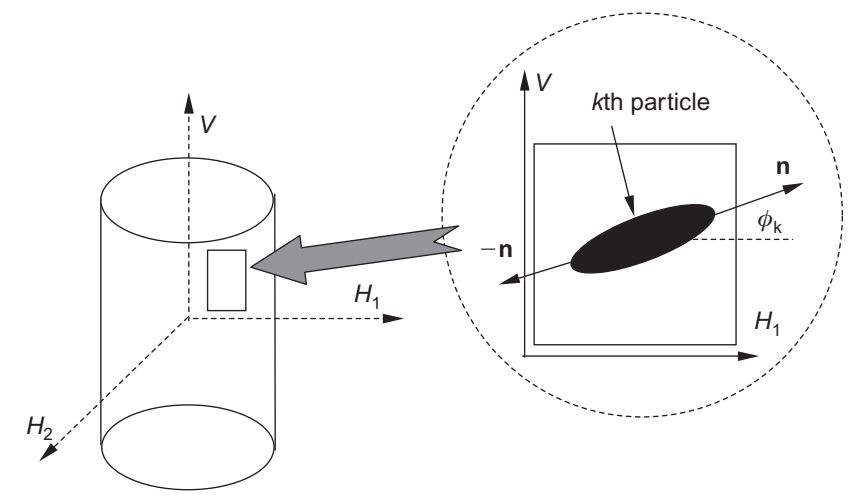

Fig. 7. Preferred particle orientation in long axis direction

major axes of all the particles are uniformly distributed in the horizontal plane $\mathrm{H}_{1}-\mathrm{H}_{2}$.

Through image processing, each particle was numbered and its orientation was identified. By statistical analysis of a number of images of the vertical sections for both DD and MT coupons, the values of $\Delta$ were computed using equation (1), and the results are summarised in Table 1. It can be seen that in the vertical plane the index $\Delta$ for DD specimens is much greater than zero, indicating that DD specimens possess obvious inherent anisotropy. By comparison, the MT samples are slightly anisotropic, since $\Delta$ is much closer to zero. The void ratio of the specimens in Table 1 was approximately $0 \cdot 863$, corresponding to the relative density of $30 \%$ of Toyoura sand. The potential relation between the vector magnitude and the void ratio was not investigated in this study, nor are there experimental data in the literature that allow a definite conclusion. This issue may deserve consideration in future studies.

The angle $\phi$ with respect to the horizontal axis in the frequency histogram and rose diagram representations are shown in Figs 8(a) and 8(b) respectively, for vertical sections. For DD specimens the preferential particle orientation is in the horizontal direction, which was caused mainly by gravitational force during the deposition process in sample preparation. For the MT specimen, however, the preferred orientation of the particles appears to be more randomly distributed, owing to the existing initial moisture in the soils. These results suggest that the DD specimens tended to be more anisotropic than the MT specimens.

Figure 9 shows the preferred orientation of the particles for the horizontal sections of both the MT and DD coupons. Compared with Fig. 8, there is no preferential particle orientation in the horizontal plane for either DD or MT specimens, and the corresponding values of the index $\Delta$ are very close to zero (Table 1). This observation provides a good justification for the transverse isotropy postulation for both DD and MT specimens.

Table 1. Values of vector magnitude for specimens prepared using different methods

\begin{tabular}{l|c|c|c|c}
\hline Sample ID & Plane & Number of particles & Vector magnitude, $\Delta$ & Average value \\
\hline DD-sample3 & Vertical & 1754 & $0 \cdot 218$ & \\
DD-sample7 & Vertical & 1015 & $0 \cdot 222$ & $0 \cdot 214$ \\
DD-sample2 & Vertical & 601 & $0 \cdot 203$ & - \\
DD-sample6 & Horizontal & 1193 & $0 \cdot 029$ & 0.091 \\
MT-sample1 & Vertical & 1636 & $0 \cdot 076$ & \\
MT-sample2 & Vertical & 1438 & $0 \cdot 113$ & - \\
MT-sample3 & Vertical & 1100 & 0.083 & 0.052 \\
MT-sample6 & Horizontal & 826 & & \\
\hline
\end{tabular}

Note: The void ratio of the samples was approximately $0 \cdot 863$. 


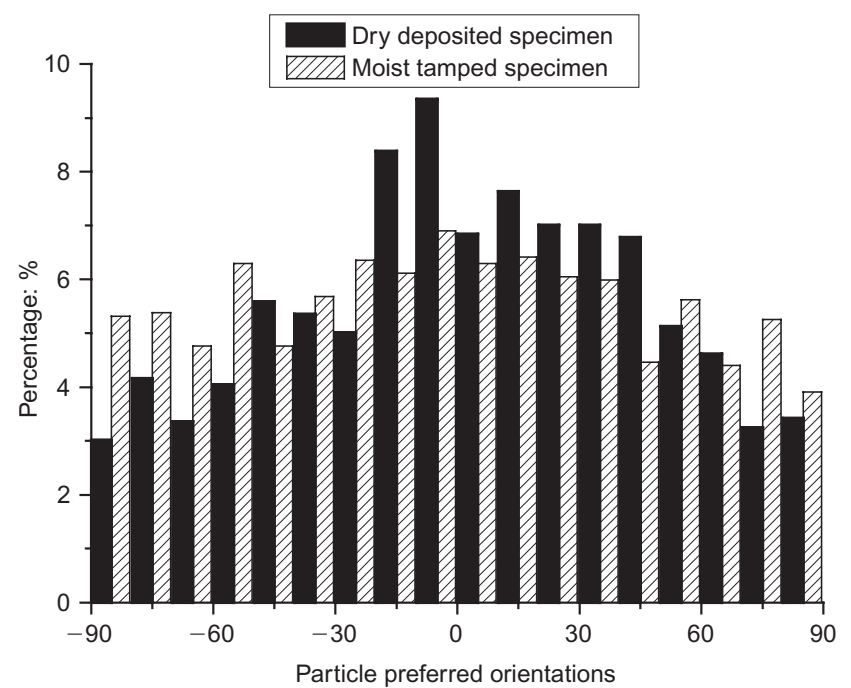

(a)

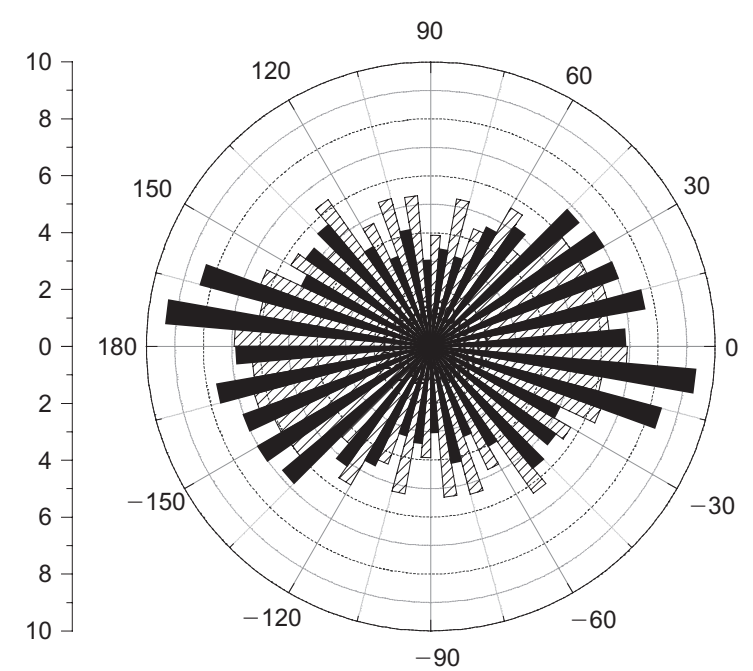

(b)

Fig. 8. Characterisation of inherent fabric anisotropy of Toyoura sand with preferred particle orientations for vertical sections: (a) histogram; (b) rose diagram representation

The orientation of a non-spherical particle can be specified by a pair of unit vectors, $\mathbf{n}$ and $-\mathbf{n}$, along its major axis of elongation. A fabric tensor of second order (Oda, 1999) can be defined as

$$
F_{i j}=\frac{1}{2 N} \sum_{k=1}^{2 N} n_{i}^{k} n_{j}^{k}
$$

where $N$ is the number of particles in a representative volume, and $n_{i}^{k}$ and $n_{j}^{k}$ are the components of the $k$ th vector. The magnitudes of the components in the tensor represent the net portion of the particles that are statistically orientated towards a particular direction. Note that $F_{i j}$ is symmetric, and therefore it can always be represented by three principal values, $F_{1}, F_{2}$ and $F_{3}$, and three associated principal directions. If the reference frame is chosen to be coincident with the principal directions, the fabric tensor can be written as

$$
F_{i j}=\left[\begin{array}{ccc}
F_{1} & 0 & 0 \\
0 & F_{2} & 0 \\
0 & 0 & F_{3}
\end{array}\right]
$$

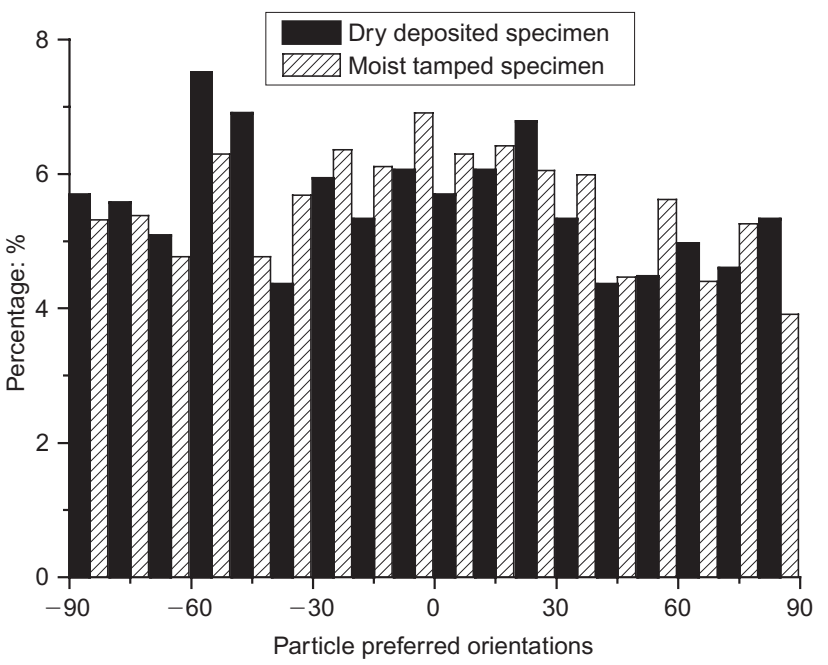

(a)

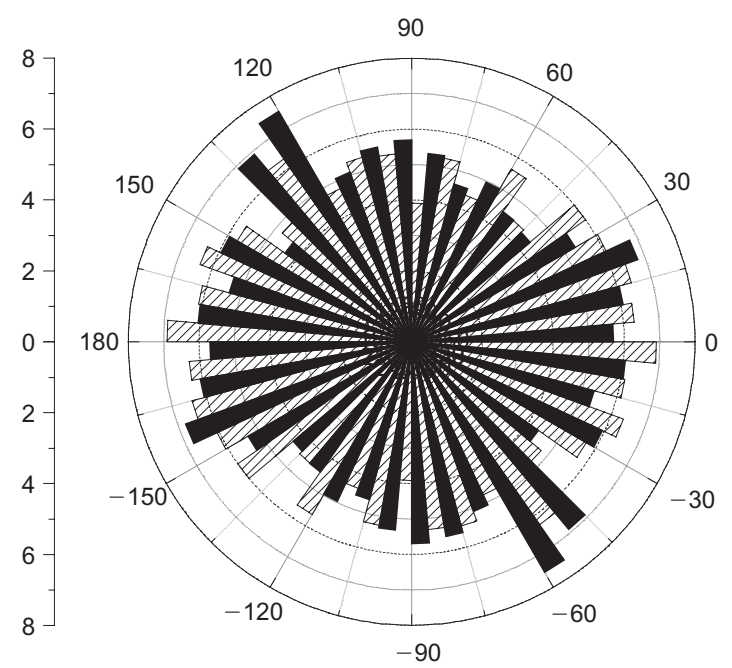

(b)

Fig. 9. Characterisation of inherent fabric anisotropy of Toyoura sand with preferred particle orientations for horizontal sections: (a) histogram; (b) rose diagram representation

In most practical cases soils are transversely isotropic: two of the principal values, say $F_{2}$ and $F_{3}$, are equal to each other, leaving only two independent principal values, $F_{1}$ and $F_{3}$, for the tensor. Furthermore, the tensor $F_{i j}$ possesses a unit trace: that is, $F_{1}=1-\left(F_{2}+F_{3}\right)=1-2 F_{3}$. Therefore, for a cross-anisotropic soil with a known direction of deposition (usually in the vertical direction), only one scalar quantity is needed to define the fabric tensor. In this case, the fabric tensor can be written as (Oda \& Nakayama, 1988)

$$
F_{i j}=\frac{1}{3+\Delta}\left[\begin{array}{ccc}
1-\Delta & 0 & 0 \\
0 & 1+\Delta & 0 \\
0 & 0 & 1+\Delta
\end{array}\right]
$$

where $\Delta$ is the vector magnitude defined earlier. By substituting the $\Delta$ value pertinent to a specific structure (DD or MT specimen) into this expression, the corresponding fabric tensor characterising the material anisotropic property can be obtained. 


\section{INCORPORATION OF ANISOTROPY EFFECTS IN MODELLING}

The impact of fabric anisotropy on granular soil response, and particularly on the flow liquefaction behaviour, warrants a serious treatment in geotechnical analysis. Recently, a plasticity platform model has been developed by $\mathrm{Li} \&$ Dafalias (2002) to tackle this problem. Details of this platform model will not be described in this paper. The focus here is, within this constitutive framework, to account for the combined effects of the initial fabric (associated with different sample preparation methods) and the loading direction (i.e. different shear modes).

Based on the work of Tobita (1988), a stress tensor $\hat{T}_{i j}$ is introduced to characterise the anisotropy effects. $\hat{T}_{i j}$ is given by

$$
\hat{T}_{i j}=\frac{1}{6}\left(\widehat{\sigma}_{i k} F_{k j}^{-1}+F_{i k}^{-1} \widehat{\sigma}_{k j}\right) \equiv \hat{p}\left(\hat{r}_{i j}+\delta_{i j}\right)
$$

in which $F_{i j}^{-1}$ is the inverse of the fabric tensor $F_{i j}$, and $\widehat{\sigma}_{i j}$ is a normalised stress given by

$$
\widehat{\sigma}_{i j}=\frac{M_{\mathrm{c}} g(\theta)}{R} r_{i j}+\delta_{i j}
$$

where $M_{\mathrm{c}}$ is a material constant, defined as the critical stress ratio under triaxial compression, and $g(\theta)$ is an interpolation function that interpolates the stress ratio invariant on the critical-state failure surface according to the Lode angle $\theta$ (Li \& Dafalias, 2002). The tensor $r_{i j}$ is defined as $r_{i j}=s_{i j} / p$, where $s_{i j}+p \delta_{i j}=\sigma_{i j}$ is the stress tensor, and $R$ is the second invariant of $r_{i j}$, defined as $R=\sqrt{3 / 2} \sqrt{r_{i j} r_{i j}}$. Note that $\widehat{\sigma}_{i j}$ represents only the loading direction associated with $r_{i j}$, not the loading magnitude.

Being a symmetric second-order tensor, $\hat{T}_{i j}$ possesses three independent isotropic invariants, among which the two non-trivial invariants pertinent to $\hat{r}_{i j}$ are $\hat{R}=\sqrt{3 \hat{r}_{i j} \hat{r}_{i j} / 2}$ and $\hat{\theta}=-\left[\sin ^{-1}\left(9 \hat{r}_{i j} \hat{r}_{j k} \hat{r}_{k i} / 2 \hat{R}^{3}\right)\right] / 3$. These two invariants can be further combined into the following single invariant to characterise the anisotropy, called the anisotropic state variable,

$$
A=\frac{\hat{R}}{M_{\mathrm{c}} g(\hat{\theta})}-1
$$

Note that if the material is isotropic, then $\Delta=0$ and $F_{i j}=$ $\delta_{i j} / 3$ : hence $\hat{T}_{i j}=\widehat{\sigma}_{i j}$ and, correspondingly, $A=0$. If the material is anisotropic, $\hat{T}_{i j}$ deviates from $\widehat{\sigma}_{i j}$, and $A$ can be either positive or negative depending on the orientation of the soil fabric relative to the loading direction and, to a lesser degree, on the fabric intensity, as shown in Fig. 10 for Toyoura sand samples. In this figure $b$ is the intermediate principal stress parameter, defined as $b=\left(\sigma_{2}-\sigma_{3}\right) /$ $\left(\sigma_{1}-\sigma_{3}\right)$, reflecting the shear mode; $\alpha$ is the angle between the direction of the major principal stress and the sample axis of transverse isotropy; and $c$ is a material constant, defined as the ratio of the critical stress ratio under triaxial extension, $M_{\mathrm{e}}$, to the ratio under triaxial compression, $M_{\mathrm{c}}$.

It follows that the combination of $\alpha=0$ and $b=0$ yields a triaxial compression loading condition, whereas $\alpha=90^{\circ}$ and $b=1$ give rise to a triaxial extension loading condition. The values of the vector magnitude $\Delta$ have been determined, based on the image analysis, to be 0.091 and 0.214 for the MT and DD specimens respectively. Note that for an MT specimen the variation of state variable $A$ is less significant than for a DD specimen: this is because the MT specimen is more isotropic than the DD specimen.

$A$ is an objective measure of the fabric anisotropy effect: that is, it is independent of the reference frame adopted. Using this objective measure, a varying critical-state line in the $e-p$ plane can be defined by making it a function of the

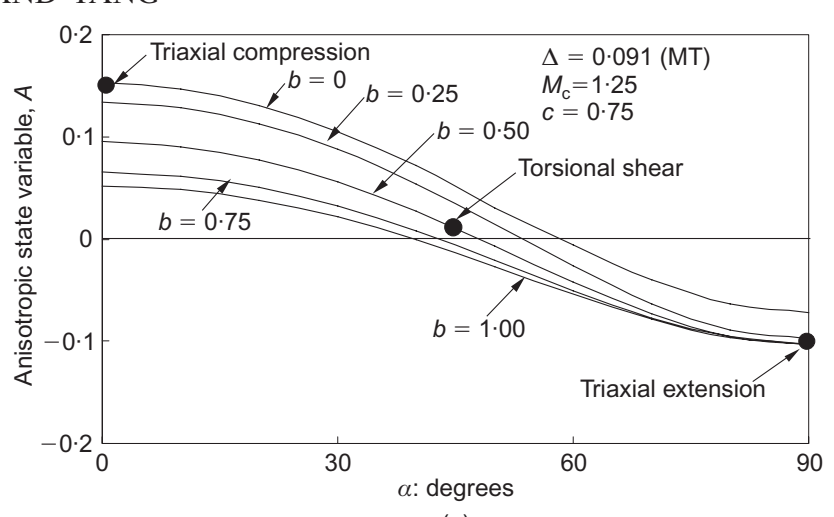

(a)

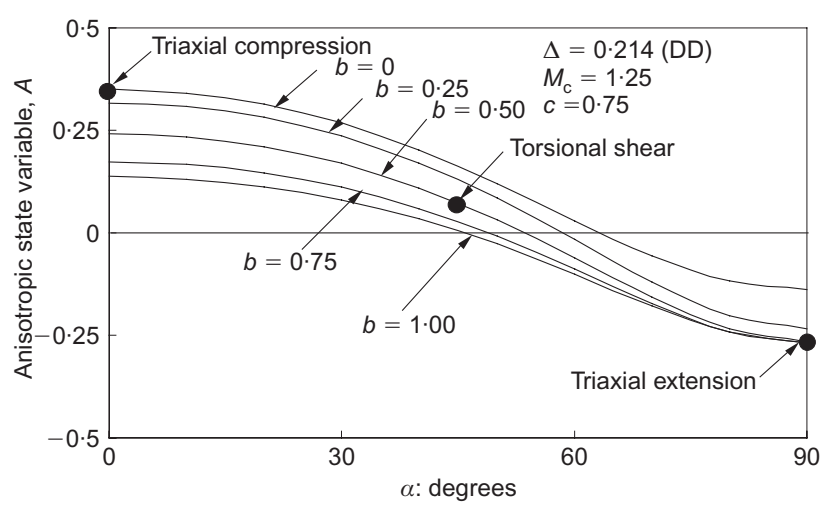

(b)

Fig. 10. Anisotropic state variable $A$ for: (a) MT specimen; (b) DD specimen

parameter $A$. Considering that the slope of this critical-state line is influenced mainly by the shape of the grains, which is an intrinsic property (Poulos et al., 1985), only $e$, the critical-state void ratio at intercept $p=0$, is made here a function of $A$ and the intermediate principal stress parameter $b$ as

$$
e_{\Gamma}=e_{\Gamma \mathrm{c}}-k_{\Gamma}\left(A_{\mathrm{c}}-A\right)(1-t \cdot b)
$$

where $e_{\Gamma \mathrm{c}}$ (the critical-state void ratio for triaxial compression at intercept $p=0), k_{\Gamma}$ and $t$ are three material constants, and $A_{\mathrm{c}}$ corresponds to the anisotropic state variable $A$ at triaxial compression.

Equation (8) creates a sequence of straight critical-state lines running parallel to each other in the $e-p$ plane (Fig. 11), which are altered for different loading paths and inherent fabric intensities. Note that the critical-state line here takes the form $e_{\mathrm{c}}=e_{\Gamma}-\lambda_{\mathrm{c}}\left(p / p_{\mathrm{a}}\right)^{\xi}$, where $\lambda_{\mathrm{c}}$ and $\xi$ are material constants, and $p_{\mathrm{a}}$ is a reference pressure $(101 \mathrm{kPa})$.

Recently, there has been accumulating evidence (e.g. Chapuis \& Soulié, 1981; Tobita, 1989; Riemer \& Seed, 1997; Chen \& Chuang, 2001) that the critical-state line in the $e-p$ plane is dependent on the initial fabric and shear mode. This argument is implicitly reflected by equation (8), because both $A$ and $A_{\mathrm{c}}$ are functions of the anisotropic parameter $\Delta$, and $e_{\Gamma}$ is also dependent on $b$. According to equation (8), if $b=0$ and $A=A_{\mathrm{c}}$, then $e_{\Gamma}=e_{\Gamma \mathrm{c}}$ : that is, the critical-state line in triaxial compression is not affected by the inherent fabric anisotropy. This is in agreement with the observation of Ishihara (1993). In the case of triaxial extension, because of the dependence of the state parameter $A$ on $\Delta, e_{\Gamma}$ for DD is less than that for MT, with the result that the critical-state line for DD specimens is located beneath that for MT (Fig. 11).

An examination of test data in the literature has suggested 

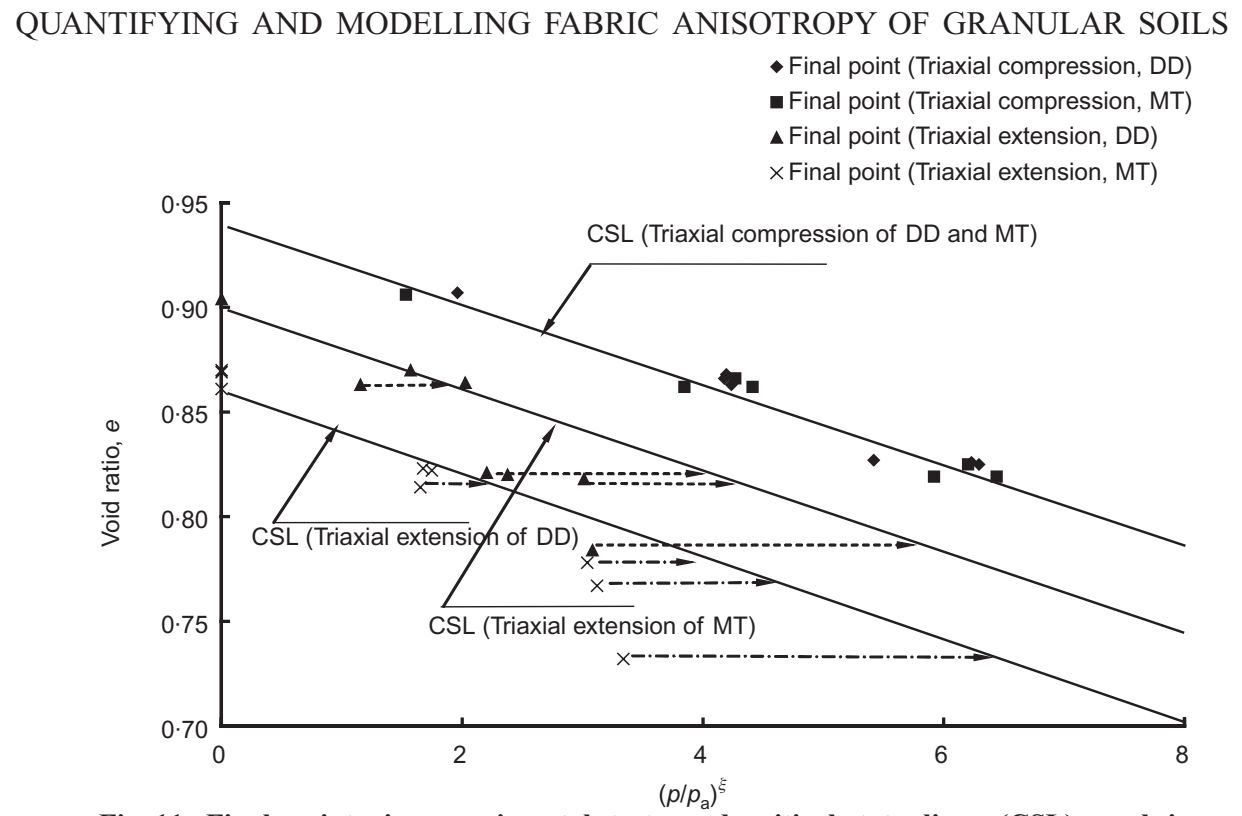

Fig. 11. Final points in experimental tests and critical-state lines (CSL) used in modelling

that the plastic modulus is also appreciably influenced by fabric anisotropy. Thus the plastic modulus is also made a function of the fabric anisotropy as

$$
K_{\mathrm{p}}=\frac{G h}{R}\left[M_{\mathrm{c}} g(\theta) \mathrm{e}^{-n \psi}-R\right]
$$

where $G$ is the elastic shear modulus, and $\psi=e-e_{\mathrm{c}}$ is the difference between the current void ratio $e$ and the criticalstate void ratio $e_{\mathrm{c}}$ corresponding to the current mean normal stress $p$. The parameter $\psi$ was referred to as the state parameter by Been \& Jefferies (1985), and has been shown to be advantageous in characterising granular soil behaviour (e.g. Wood et al., 1994; Manzari \& Dafalias, 1997; Li \& Dafalias, 2000; Yang \& Li, 2004). The quantity $n$ is a model constant, and $h$ is a scaling factor, defined as

$$
h=\left(h_{1}-h_{2} e\right) \frac{\left(k_{h} A_{\mathrm{c}}-A_{\mathrm{e}}\right)+\left(1-k_{h}\right) A}{A_{\mathrm{c}}-A_{\mathrm{e}}}
$$

where $k_{h}$ is a new material constant. It can be seen that $h$ varies linearly with $A$. When $A=A_{\mathrm{c}}$ (triaxial compression at $\alpha=0^{\circ}$ ), $h=h_{1}-h_{2} e$. When $A=A_{\mathrm{e}}$ (triaxial extension at $\left.\alpha=90^{\circ}\right), h=\left(h_{1}-h_{2} e\right) k_{h}$ : that is, $h$ is scaled by a factor $k_{h}$. By including the dependence of the critical-state line and the plastic modulus on $A$, this model is capable of simulating test results involving various loading directions with respect to the soil fabric coordinate, as will be shown later.

Following the work of $\mathrm{Li} \&$ Dafalias (2000), the statedependent dilatancy is given as

$$
D=\frac{d_{1}}{M_{\mathrm{c}} g(\theta)}\left[1+\frac{R}{M_{\mathrm{c}} g(\theta)}\right]\left[M_{\mathrm{c}} g(\theta) \mathrm{e}^{m \psi}-R\right]
$$

where $d_{1}$ and $m$ are two material constants. Note that a varying critical-state line in the $e-p$ plane will make the state parameter $\psi$ a function of both the major principal stress direction and the soil fabric, which in turn makes the soil dilatancy both fabric and stress path dependent.

\section{LABORATORY TESTS AND MODEL SIMULATIONS}

A series of undrained tests, including triaxial compression $(b=0)$, triaxial extension $(b=1 \cdot 0)$ and torsional shear $(b$
$=0 \cdot 5)$ tests, was performed on Toyoura sand. Both the DD and MT methods were used to prepare soil specimens. Two different void ratios and three initial effective confining pressures $(100,200$ and $400 \mathrm{kPa})$ were considered. A combination of different conditions gave rise to a total of 30 tests, as listed in Table 2.

All test results are shown in Figs $12-16$ with the label Experiment. The data are presented in the $q-p$ and $q-\varepsilon_{q}$ planes, where $\varepsilon_{q}$ is deviatoric strain. It can be seen that, compared with triaxial compression, the sand behaviour under the triaxial extension condition is much more contractive and softer, with the torsional shear in between. Further, the sand responses in triaxial extension and torsional shear modes were found to be more significantly affected by the specimen preparation method than the response in triaxial compression. The contractive response and softening behaviour are observed in all the tests performed on the DD specimens under either triaxial extension or torsional shear conditions, whereas for the MT specimens dilative behaviour appears to be dominant when the shear strain exceeds a certain level. The underlying reasoning for the above observations is that the critical-state line determined by the triaxial extension tests lies to the left of that determined by the compression tests in the $e-\ln p$ plane (Fig. 11), and the differences between compression and extension lines for the DD samples are much larger than for the MT samples.

All the test results have been simulated by the anisotropic model described in the preceding section, with a unified set of model parameters (Table 3). These parameters can be divided into four groups according to their functions: elastic parameters; critical-state parameters; anisotropic parameters; and parameters associated with dilatancy. Most of the calibrated model constants are consistent with those used in $\mathrm{Li}$ \& Dafalias (2002), except for those that are related to the sample preparation methods and the shear-mode-dependent critical-state line. The model predictions are presented together with the experimental data in Figs 12-16.

It is seen that the model can capture the general trend of the various sand behaviours associated with the anisotropic effects and the density and pressure dependence. The observed discrepancies are considered to be related mainly to

(a) the uncertainty in experimental determination of the critical-state line in the $e-p$ plane 
Table 2. Summary of laboratory tests conducted

\begin{tabular}{|c|c|c|c|c|}
\hline & $\begin{array}{l}\text { Sample preparation } \\
\text { method }\end{array}$ & $\begin{array}{c}\text { Relative density: } \\
\%\end{array}$ & $\begin{array}{c}\text { Confining pressure: } \\
\mathrm{kPa}\end{array}$ & $\begin{array}{l}\text { Loading } \\
\text { path }\end{array}$ \\
\hline \multirow[t]{6}{*}{ Series I-a } & DD & 30 & 100 & TC \\
\hline & DD & 30 & 200 & $\mathrm{TC}$ \\
\hline & DD & 30 & 400 & $\mathrm{TC}$ \\
\hline & DD & 41 & 100 & $\mathrm{TC}$ \\
\hline & DD & 41 & 200 & $\mathrm{TC}$ \\
\hline & DD & 41 & 400 & $\mathrm{TC}$ \\
\hline \multirow[t]{6}{*}{ Series I-b } & MT & 30 & 100 & $\mathrm{TC}$ \\
\hline & MT & 30 & 200 & TC \\
\hline & MT & 30 & 400 & $\mathrm{TC}$ \\
\hline & MT & 41 & 100 & $\mathrm{TC}$ \\
\hline & MT & 41 & 200 & $\mathrm{TC}$ \\
\hline & MT & 41 & 400 & $\mathrm{TC}$ \\
\hline \multirow[t]{6}{*}{ Series II-a } & DD & 30 & 100 & TE \\
\hline & DD & 30 & 200 & TE \\
\hline & DD & 30 & 400 & TE \\
\hline & DD & 41 & 100 & $\mathrm{TE}$ \\
\hline & DD & 41 & 200 & TE \\
\hline & DD & 41 & 400 & TE \\
\hline \multirow[t]{6}{*}{ Series II-b } & MT & 30 & 100 & TE \\
\hline & MT & 30 & 200 & TE \\
\hline & MT & 30 & 400 & TE \\
\hline & MT & 41 & 100 & TE \\
\hline & MT & 41 & 200 & TE \\
\hline & MT & 41 & 400 & TE \\
\hline \multirow[t]{3}{*}{ Series III-a } & DD & 30 & 100 & TS \\
\hline & DD & 30 & 200 & TS \\
\hline & DD & 30 & 400 & TS \\
\hline \multirow[t]{3}{*}{ Series III-b } & MT & 30 & 100 & TS \\
\hline & MT & 30 & 200 & TS \\
\hline & MT & 30 & 400 & TS \\
\hline
\end{tabular}

Notes: $\mathrm{DD}=$ dry deposition; $\mathrm{MT}=$ moist tamping; $\mathrm{TC}=$ triaxial compression; $\mathrm{TE}=$ triaxial extension; $\mathrm{TS}=$ torsional shear.
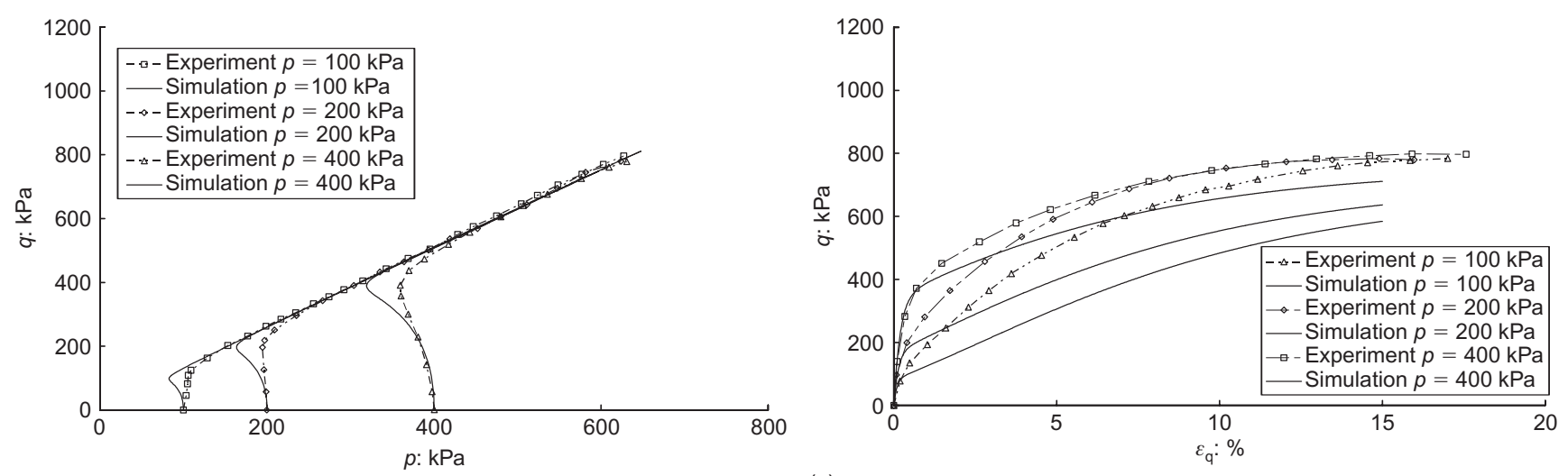

(a)
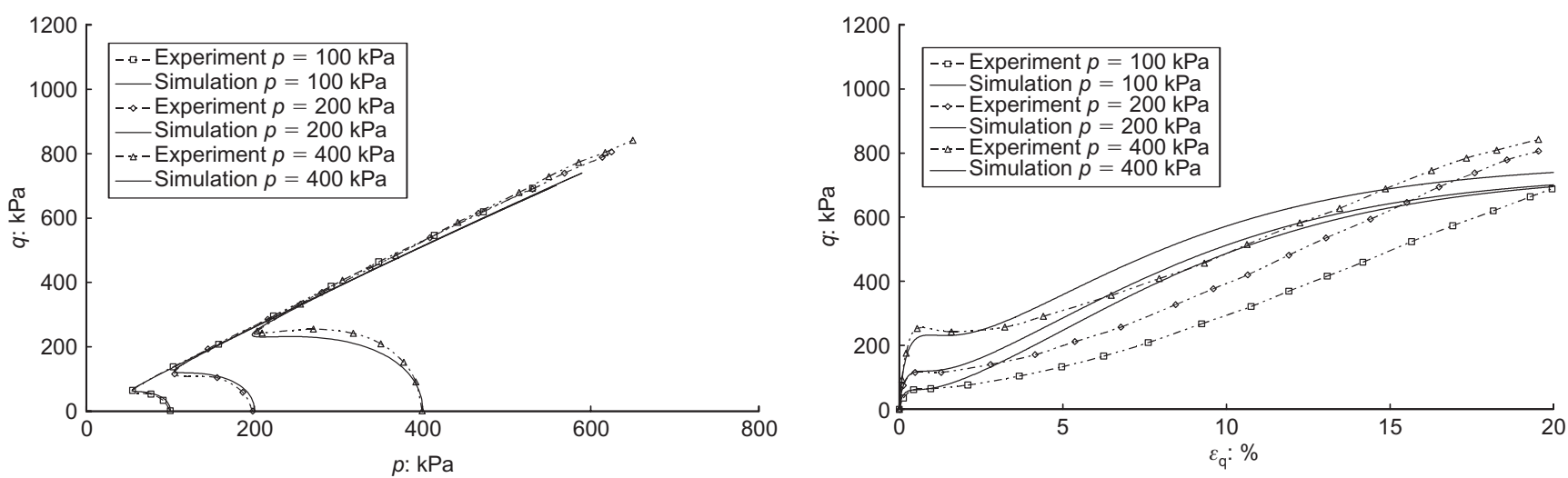

(b)

Fig. 12. Comparison between undrained triaxial compression test results and model responses for (a) MT and (b) DD specimens with $D_{\mathrm{r}}=30 \%$ 

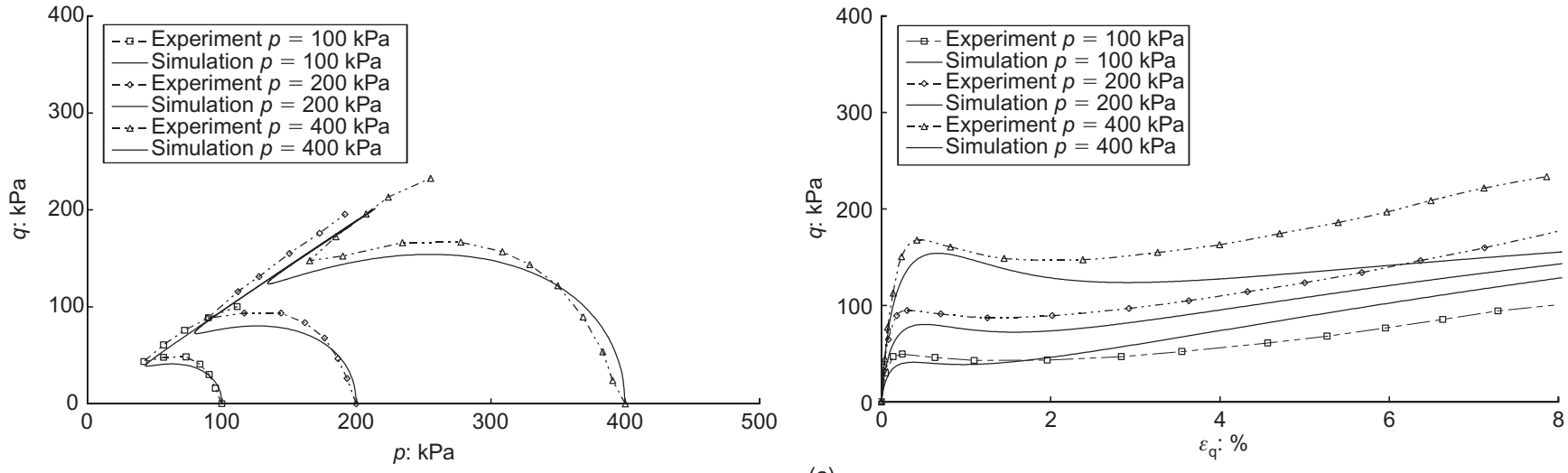

(a)
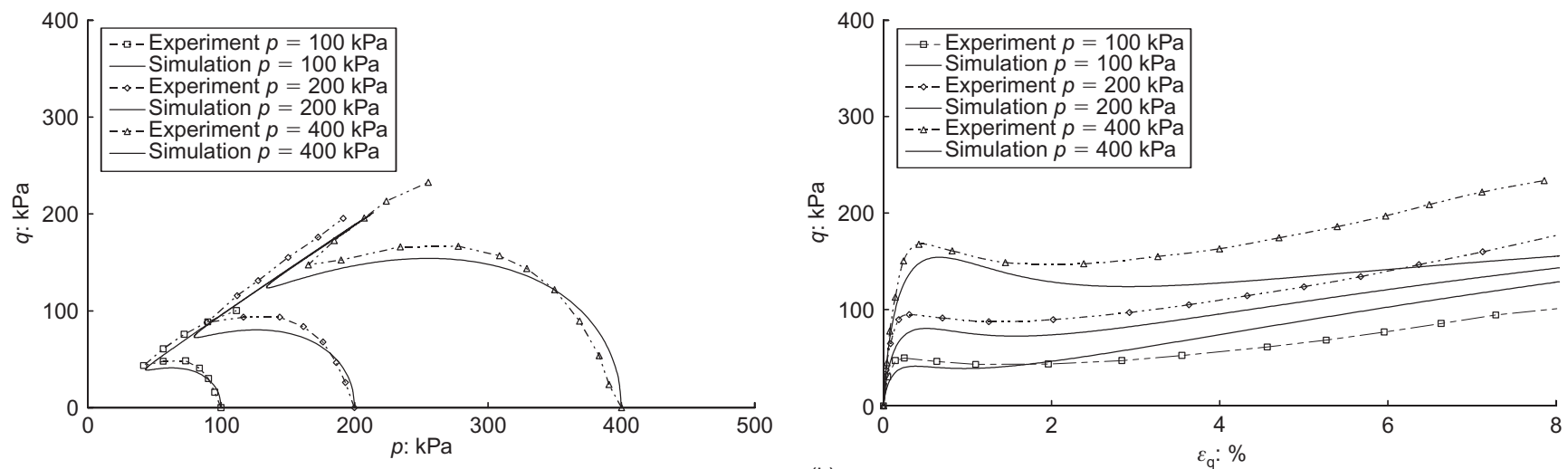

(b)

Fig. 13. Comparison between undrained triaxial extension test results and model responses for (a) MT and (b) DD specimens with $D_{\mathrm{r}}=30 \%$
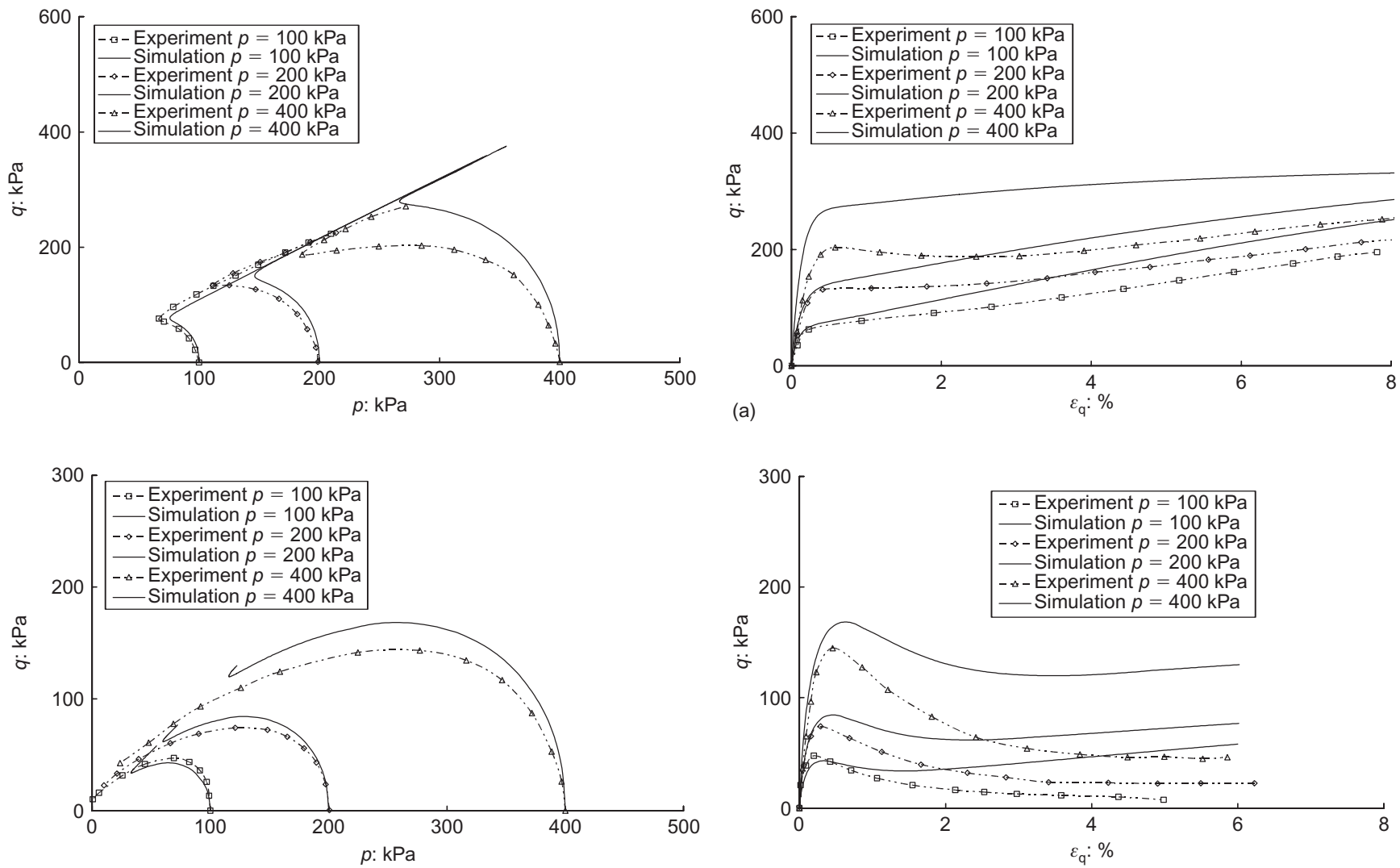

(b)

Fig. 14. Comparison between undrained torsional shear test results and model responses for (a) MT and (b) DD specimens with $D_{\mathrm{r}}=30 \%$ 

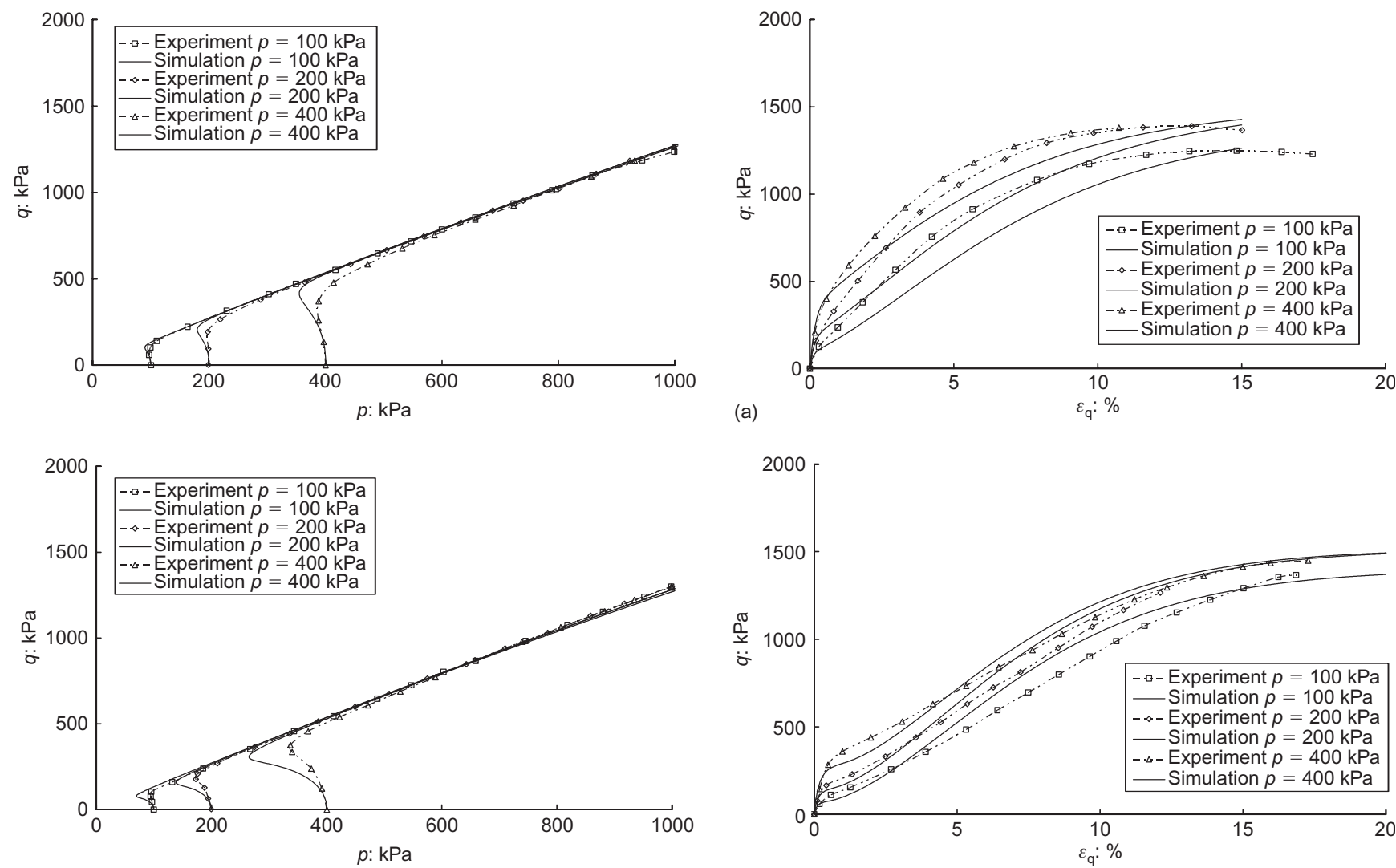

(b)

Fig. 15. Comparison between undrained triaxial compression test results and model responses for (a) MT and (b) DD specimens with $D_{\mathrm{r}}=41 \%$
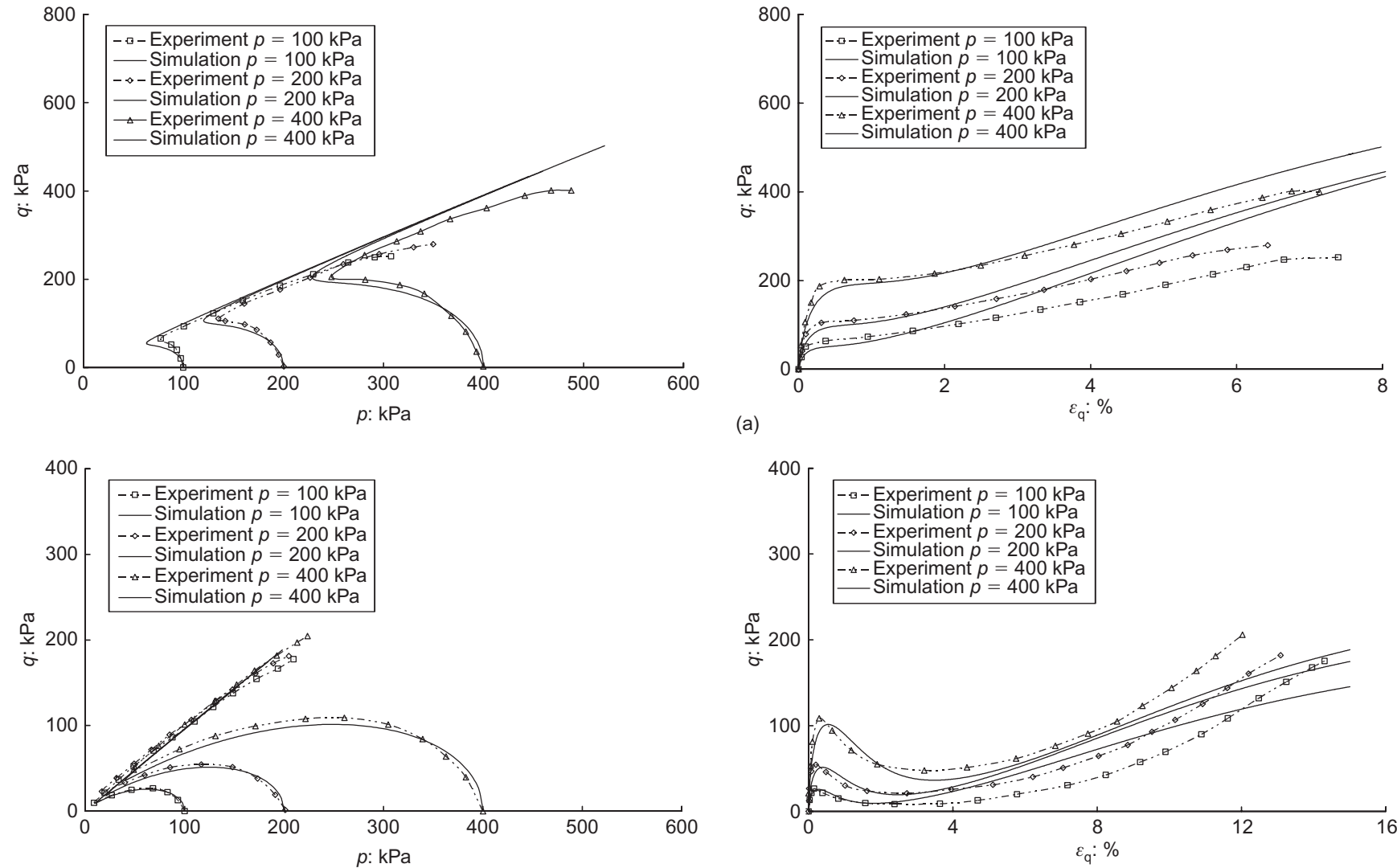

(b)

Fig. 16. Comparison between undrained triaxial extension test results and model responses for (a) MT and (b) DD specimens with $D_{\mathrm{r}}=41 \%$ 
Table 3. Model constants for Toyoura sand

\begin{tabular}{l|c|c|c}
\hline $\begin{array}{l}\text { Elastic } \\
\text { parameters }\end{array}$ & $\begin{array}{c}\text { Critical-state } \\
\text { parameters }\end{array}$ & $\begin{array}{c}\text { Anisotropic } \\
\text { parameter }\end{array}$ & $\begin{array}{c}\text { Parameters associated with } \\
\text { dilatancy }\end{array}$ \\
\hline$G_{0}=125$ & $M_{\mathrm{c}}=1.25$ & $\Delta^{\mathrm{DD}}=0.214$ & $h_{1}^{\mathrm{DD}}=3.45$ \\
$v=0.25$ & $c=0.75$ & $\Delta^{\mathrm{MT}}=0.091$ & $h_{1}^{\mathrm{MT}}=3.5 \times h_{1}^{\mathrm{DD}}$ \\
& $e_{\Gamma \mathrm{c}}=0.933$ & $k_{h}=0.2$ & $h_{2}^{\mathrm{DD}}=3.34$ \\
& $k_{\Gamma}=0.22$ & $n=1.1$ & $h_{2}^{\mathrm{MT}}=3.5 \times h_{2}^{\mathrm{DD}}$ \\
& $t=0.45$ & & $d_{1}=0.38$ \\
& $\lambda_{\mathrm{c}}=0.02$ & & $m=1.0$ \\
& $\xi=0.7$ & & \\
\hline
\end{tabular}

Note: The superscripts MT and DD denote constants for MT and DD specimens respectively.

(b) the simplified assumption that the critical-state line in triaxial extension is parallel to that in triaxial compression

(c) the influence of non-uniformity of soil samples at large strains on test data

(d) the evolution of the fabric tensor and the influence of the fabric anisotropy on plastic yielding.

These discrepancies suggest the need for more experimental data at both the microscopic and macroscopic levels, and for further improvements of the constitutive model in the future.

\section{CONCLUSIONS}

Accumulating evidence has shown that the undrained response of a granular soil depends very much on the sample preparation method as well as on the shear mode, calling for a serious treatment of the impact of fabric anisotropy in geotechnical analysis. This paper describes an integrated study of the problem in which a microscopic quantification of the inherent fabric of granular soil specimens is properly linked with a macroscopic modelling of various anisotropic responses.

Using an image-analysis-based technique, the distinctly different fabrics of Toyoura sand specimens prepared in the laboratory using the dry deposition (DD) and moist tamping (MT) methods were measured and quantified at the microscale level. It is found that the sand samples prepared by the DD and MT methods can be reasonably assumed to be transversely isotropic, with the vertical direction as the axis of symmetry. In the vertical plane, the DD specimens possess obviously inherent anisotropy, whereas the MT samples tend to be more isotropic. The vector magnitude and the fabric tensor are shown to be useful indices for characterising the soil fabric.

An existing platform model has been extended so that the inherent fabric anisotropy and shear mode dependence are accounted for in a rational yet simple manner. This is achieved by rendering the location of the critical-state line in the $e-p$ plane and the plastic modulus functions of the anisotropic state variable, the major principal stress direction and the intermediate principal stress parameter.

A structured testing programme has been carried out for Toyoura sand to investigate various combined effects of principal stress directions, intermediate principal stress values, sample preparation methods, soil densities and confining pressures. A detailed comparison of the model responses and experimental results shows the capability of the constitutive model in capturing the complicated anisotropic effects of granular soils.

\section{ACKNOWLEDGEMENTS}

The financial support provided by the Research Grants Council of Hong Kong (600202) is gratefully acknowledged.

\section{NOTATION}

$A, A_{\mathrm{c}}, A_{\mathrm{e}}$ anisotropic parameters

$b$ intermediate principal stress parameter

$c$ intrinsic material constant

CSL critical-state line

$D$ dilatancy

$D_{\mathrm{r}}$ relative density

$e, e_{\mathrm{c}}$ void ratio, critical-state void ratio

$F_{i j}, F_{i j}^{-1}$ fabric tensor, inverse of fabric tensor

${ }_{G}$ elastic shear modulus

$g(\theta)$ interpolation function

$K_{\mathrm{p}}$ plastic modulus

$M_{\mathrm{c}}, M_{\mathrm{e}}$ critical stress ratios at triaxial compression and extension respectively

$p$ mean effective stress

$p_{\mathrm{a}} \quad$ atmospheric pressure $=101 \mathrm{kPa}$

$\hat{p} \quad$ hydrostatic component of $\hat{T}_{i j}$

$\hat{R}$ invariant of $\hat{r}_{i j}$

$r_{i j}$ stress ratio tensor

$\hat{r}_{i j}$ deviatoric stress ratio tensor of $\hat{T}_{i j}$

$s_{i j} \quad$ deviatoric stress tensor

$\hat{T}_{i j}$ modified stress tensor

$\alpha$ angle between principal stress and fabric

$\Delta$ vector magnitude

$\delta_{i j} \quad$ Kronecker delta

$\hat{\theta}$ Lode angle of $\hat{r}_{i j}$

$\sigma_{1}, \sigma_{2}, \sigma_{3}$ principal stress components

$\sigma_{i j}$ stress tensor

$\widehat{\sigma}_{i j}$ normalised stress tensor

$\phi$ angle of long axis of particle to horizontal direction

$\psi$ state parameter

\section{REFERENCES}

Been, K. \& Jefferies, M. G. (1985). A state parameter for sands. Géotechnique 35, No. 2, 99-112.

Chapuis, R. P. \& Soulié, M. (1981). Internal structure and mechanical behavior of granular soil. In Mechanics of structured media (ed. A. P. S. Selvadurai), pp. 341-355. Amsterdam: Elsevier.

Chen, Y. C. \& Chuang, J. C. (2001). Effects of fabric on steady state and liquefaction resistance. Proc. $11^{\text {th }}$ Int. Offshore and Polar Engineering Conf., Stavanger, 524-529.

Curray, J. R. (1956). The analysis of two-dimensional orientation data. J. Geol. 64, No. 2, 117-131.

Finn, W. D. L. (2000). Post-liquefaction flow deformations. In Soil dynamics and liquefaction 2000 (eds R. Y. S. Pak \& J. Yamamura), Geotechnical Special Publications No. 107, pp. 108-122. Reston, VA: ASCE.

Ishihara, K. (1993). Liquefaction and flow failure during earthquakes. Géotechnique 43, No. 3, 351-415. 
Jang, D. J., Frost, J. D. \& Park, J. Y. (1999). Preparation of epoxy impregnated sand coupons for image analysis. Geotech. Test. J. 22, No. 2, 147-158.

Kuerbis, R. \& Vaid, Y. P. (1988). Sand sample preparation: the slurry deposition method. Soils Found. 28, No. 4, 107-118.

Kuo, C. Y. \& Frost, J. D. (1996). Uniformity evaluation of cohesionless specimens using digital image analysis. J. Geotech. Geoenviron. Engng ASCE 122, No. 5, 390-396.

Li, X. S. \& Dafalias, Y. F. (2000). Dilatancy for cohesionless soils. Géotechnique 50, No. 4, 449-460.

Li, X. S. \& Dafalias, Y. F. (2002). Constitutive modeling of inherently anisotropic sand behavior. J. Geotech. Geoenviron. Engng ASCE 128, No. 10, 868-880.

Manzari, M. T. \& Dafalias, Y. F. (1997). A critical state two-surface plasticity model for sands. Géotechnique 47, No. 2, 255-272.

Miura, S. \& Toki, S. (1982). A sample preparation method and its effect on static and cyclic deformation-strength properties of sand. Soils Found. 22, No. 1, 61-77.

Oda, M. (1999). Fabric tensor and its geometrical meaning. In Introduction to mechanics of granular materials (eds M. Oda and K. Iwashita), pp. 27-34. Rotterdam: A. A. Balkema.

Oda, M. \& Nakayama, H. (1988). Introduction of inherent anisotropy of soils in the yield function. In Micromechanics of granular materials (eds M. Satake \& J. T. Jenkins), pp. 81-90. Amsterdam: Elsevier Science.

Poulos, S. J., Castro, G. \& France, J. W. (1985). Liquefaction evaluation procedure. J. Geotech. Engng ASCE 111, No. 6, $772-792$.

Riemer, M. F. \& Seed, R. B. (1997). Factors affecting apparent position of steady-state line. J. Geotech. Geoenviron. Engng ASCE 123, No. 3, 281-288.

Seed, H. B., Seed, R. B., Harder, L. F. Jr \& Jong, H. L. (1989). Reevaluation of the low San Fernando dam. Report No. 2, Exam- ination of the post-earthquake slide of February 9, 1971. Washington, DC: Department of the Army, US Army Corps of Engineers.

Tatsuoka, F., Ochi, K., Fujii, S. \& Okamoto, M. (1986). Cyclic undrained triaxial and torsional shear strength of sands for different sample preparation methods. Soils Found. 26, No. 3, 23-41.

Tobita, Y. (1988). Contact tensor in constitutive model for granular materials. Proceedings of the US-Japan seminar on micromechanics of granular materials, Sendai, pp. 263-270.

Tobita, Y. (1989). Fabric tensors. In Mechanics of granular materials, Report from TC13, International Society of Soil Mechanics and Foundation Engineering (ed. M. Satake), pp. 6-9. International Society of Soil Mechanics and Foundation Engineering.

Vaid, Y. P. \& Chern, J. C. (1985) Cyclic and monotonic undrained response of saturated sands. Proc. ASCE Nat. Conv. Advances in the art of testing soils under cyclic loading, Detroit, pp. 120147.

Vaid, Y. P., Sivathayalan, S. \& Stedman, D. (1999). Influence of specimen reconstituting method on the undrained response of sand. Geotech. Test. J. 22, No. 3, 187-195.

Wood, M. D., Belkheir, K. \& Liu, D. F. (1994). Strain softening and state parameter for sand modelling. Géotechnique 44, No. 2, 335-339.

Yang, J. (2002). Non-uniqueness of flow liquefaction line for loose sand. Géotechnique 52, No. 10, 757-760.

Yang, J. \& Li, X. S. (2004). State-dependent strength of sands from the perspective of unified modeling. J. Geotech. Geoenviron. Engng ASCE 130, No. 2, 186-198.

Yoshimine, M., Ishihara, K. \& Vargas, W. (1998). Effects of principal stress direction and intermediate principal stress on undrained shear behavior of sand. Soils Found. 38, No. 3, 179188 . 